\title{
CrystEngComm
}

Check for updates

Cite this: CrystEngComm, 2021, 23, 5899

Received 3rd April 2021,

Accepted 10th June 2021

DOI: $10.1039 /$ d1ce00445j

rsc.li/crystengcomm

\section{Multi-color mechanochromic luminescence of three polymorphic crystals of a donor-acceptor- type benzothiadiazole derivative $\uparrow$}

\author{
Suguru Ito, (D) *a Sayaka Nagai, ${ }^{a}$ Takashi Ubukata (D) a and Takashi Tachikawa (D) bc
}

\begin{abstract}
The past decade has witnessed rapid advances in the development of organic crystals that exhibit mechanochromic luminescence $(M C L)$, i.e., the reversible color change of photoluminescence induced by mechanical force. However, a greater understanding of the correlation between the MCL properties and the molecular structures in the crystalline state is still necessary to rationally control the photophysical and mechanical properties of organic crystals. Herein, a thienyl-substituted benzothiadiazole derivative is described as a new donor-acceptor-type MCL dye that crystallizes in three polymorphic forms. Both bicolor and tricolor MCL have been realized by the single donor-acceptor-type dye. The green-emissive polymorph exhibits typical bicolor MCL between green and orange based on crystal-to-amorphous phase transitions. Meanwhile, the yellow and yellow-orange-emissive crystals show tricolor emission-color switching. Specifically, the emission color of the yellow-emissive crystals changed to yellowish orange and orange in response to thermal and mechanical stimuli, respectively. The yelloworange-emissive crystals display bicolor MCL between yellow-orange and orange emission. The singlecrystal X-ray diffraction analyses of the polymorphic crystals indicated that the emission color of these crystals should be determined by the dihedral angle between benzothiadiazole and thiophene rings as well as the mode of packing structures. This study reinforces the understanding of the MCL of polymorphic crystals, which should help to advance the possible applications of MCL crystals in multicolor mechanosensing systems.
\end{abstract}

\section{Introduction}

Mechanical stimuli are ubiquitous external stimuli that regulate the physical properties of materials. In the past decade, great advances have been made in the development of mechanical stimuli-responsive organic and organometallic crystals. ${ }^{1}$ One fascinating phenomenon that crystalline compounds exhibit upon mechanical stimulation is a reversible color change of photoluminescence, which is referred to as mechanochromic luminescence (MCL). A

\footnotetext{
${ }^{a}$ Department of Chemistry and Life Science, Graduate School of Engineering Science, Yokohama National University, 79-5 Tokiwadai, Hodogaya-ku, Yokohama 240-8501, Japan. E-mail: suguru-ito@ynu.ac.jp

${ }^{b}$ Department of Chemistry, Graduate School of Science, Kobe University, 1-1 Rokkodai-cho, Nada-ku, Kobe 657-8501, Japan

${ }^{c}$ Molecular Photoscience Research Center, Kobe University, 1-1 Rokkodai-cho, Nada-ku, Kobe 657-8501, Japan

$\dagger$ Electronic supplementary information (ESI) available: X-ray structures, supplementary spectra, DSC thermograms, fluorescence lifetimes, theoretical calculations, PXRD data and NMR spectra. CCDC 2073080-2073082 For ESI and crystallographic data in CIF or other electronic format see DOI: 10.1039/ d1ce00445j
}

considerable number of organic ${ }^{2}$ and organometallic ${ }^{3}$ MCL crystals have been developed as these materials should find applications in advanced optoelectronic technologies, including mechanosensors, security devices, and rewritable media. Most of the hitherto reported MCL crystals exhibit bicolor emission-color switching based on mechanical stimuli-induced phase transitions between crystalline and amorphous phases. ${ }^{4}$ Changes in molecular conformations and intermolecular interactions caused by phase transitions result in the switching of emission properties..$^{1 f}$ Despite recent significant progress in the development of MCL crystals, a more detailed understanding of the relationship between crystal structure and emission properties is required to be able to ultimately design and predict the MCL properties of luminescent compounds.

Polymorphic and pseudopolymorphic (solvent-including) crystals provide an opportunity to understand the effect of packing modes on the photoluminescence properties of a single compound. ${ }^{5-7}$ Several (pseudo)polymorphic crystals have been reported to exhibit different MCL properties depending on their packing structures. ${ }^{8-10}$ Multi-color emission switching has also been achieved based on the different emission and stimuli-responsive properties of 
(pseudo)polymorphic crystals. However, little is known for the MCL properties of organic compounds that can be crystallized as both polymorphic and pseudopolymorphic crystals. ${ }^{10 b, e}$

Donor-acceptor-type organic crystalline compounds often exhibit MCL because their photoluminescence properties are variable depending on the surrounding environment. ${ }^{11} \mathrm{We}$ have recently reported the versatile MCL properties of donoracceptor-type organic dyes composed of an electron-donating heteroaromatic ring and electron-accepting 2,1,3benzothiadiazole ring. ${ }^{12}$ Among these, derivatives having triphenylimidazole groups as electron-donating rings are promising to provide a deep understanding of the relationship between crystal structures and MCL properties. Pseudopolymorphic crystals ${ }^{12 e}$ and morphologically different crystals $^{12 b}$ were obtained for 4-(triphenylimidazolyl)-2,1,3benzothiadiazole derivatives depending on the substituent on the 7-position of the benzothiadiazole ring. The crystal structure and MCL properties of these crystals are mainly determined by the steric rather than the electronic effects of the substituents.

Herein, we report the MCL behaviors of polymorphic and pseudopolymorphic crystals of a donor-acceptor-type benzothiadiazole derivative 1 . The molecular structure of 1 is based on the introduction of a 2-thienyl group at the 7-position of 4-(triphenylimidazolyl)-2,1,3-benzothiadiazole (Fig. 1a). Two polymorphic and one pseudopolymorphic crystals have been obtained for this new donor-acceptor-type dye 1. These (pseudo)polymorphic crystals exhibit different emission colors from green to yellow and yellowish orange. Remarkably, the green-emissive crystals show bicolor MCL, whereas tricolor emission switching has been observed for the yellow and yellow-orange-emissive crystals. Based on the single-crystal X-ray diffraction analyses, we propose that the rotational angle of the thienyl group relative to the (a)

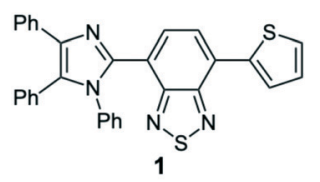

(c)

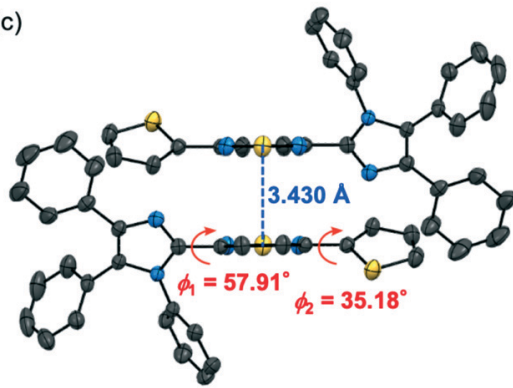

(b) Crystal $\alpha$

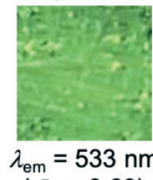
$\lambda_{\mathrm{em}}=533 \mathrm{~nm}$
$\left(\Phi_{\mathrm{F}}=0.60\right)$

(d)

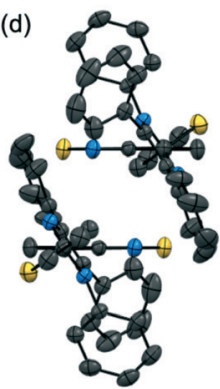

Fig. 1 (a) Molecular structure of 1. (b) Photographs of the MCL of 1- $\alpha$ $\left(\lambda_{\mathrm{ex}}=365 \mathrm{~nm}\right)$. (c) Front view and (d) side view of 1- $\alpha$ for the two molecules in spatial proximity with thermal ellipsoids at $50 \%$ probability. All hydrogen atoms are omitted for clarity. Color code: gray $=\mathrm{C}$; blue $=\mathrm{N}$; yellow $=\mathrm{S}$. benzothiadiazole plane as well as molecular packing structures should determine the emission wavelength and MCL behavior of these crystals.

\section{Results and discussion}

\section{Synthesis and MCL of 1- $\alpha$}

A thienyl-substituted derivative 1 was synthesized by the SuzukiMiyaura coupling between 4-bromo-7-(1,4,5-triphenyl- $1 \mathrm{H}^{-}$ imidazol-2-yl)benzo[c][1,2,5] thiadiazole ${ }^{12 e}$ and 2-thienylboronic acid in $83 \%$ yield (Scheme S1, ESI $\dagger$ ). Crystalline samples of 1 (abbreviated henceforth as 1- $\alpha$ ) were prepared by vapor diffusion of hexane into a toluene solution of $\mathbf{1}$. Upon irradiation with UV light $\left(\lambda_{\mathrm{ex}}=365 \mathrm{~nm}\right), \mathbf{1 - \alpha}$ showed green emission with a maximum emission wavelength $\left(\lambda_{\mathrm{em}}\right)$ of $533 \mathrm{~nm}$ and good fluorescence quantum yield $\left(\Phi_{\mathrm{F}}\right)$ of 0.60 (Fig. 1b). The X-ray diffraction analysis of $1-\alpha$ revealed that 1- $\alpha$ shows the triclinic space group $P \overline{1}$, whereby two molecules of $\mathbf{1}$ are stacked in an antiparallel manner at the benzothiadiazole moieties (Fig. 1c and $\mathrm{S} 1, \mathrm{ESI}+$ ). The two benzothiadiazole rings are in a typical $\pi$-stacking distance of $3.430 \AA$. Owing to the twisted conformations between the imidazole and benzothiadiazole rings $\left(\phi_{1}=57.91^{\circ}\right)$, the $N$-phenyl groups of the imidazole rings are located at the top and bottom of the stacked benzothiadiazole rings (Fig. 1d). The good $\Phi_{\mathrm{F}}$ value of 1- $\alpha$ should be explained by the prevention of any further aggregation of benzothiadiazole rings by these $N$-phenyl groups.

The bicolor MCL of 1- $\alpha$ should be based on the formation of an amorphous state in response to mechanical stimuli and the recrystallization of the amorphous state upon thermal stimuli. When the crystalline samples of $1-\alpha$ were ground into a fine powder by using a spatula, the emission color changed from green to yellow $\left(\lambda_{\mathrm{em}}=580 \mathrm{~nm}, \Phi_{\mathrm{F}}=0.49\right.$; Fig. $1 \mathrm{~b}$ and $\mathrm{S} 4 \mathrm{a}, \mathrm{ESI} \dagger$ ). The original green emission was recovered after heating the ground sample to $150{ }^{\circ} \mathrm{C}$. Both the absorption and excitation spectra of the yellow-emissive state shifted in the bathochromic direction compared with those of the green-emissive crystalline 1- $\alpha$ (Fig. S5a and $\mathrm{S} 5 \mathrm{~b} \dagger)$. These results indicate that the difference in the ground state structures should contribute to the switching of the emission color. Powder X-ray diffraction (PXRD) analysis showed a significant decrease in the intensity of the diffraction pattern after grinding. Although the ground sample still showed some weak diffraction peaks, most of the crystal structures should be decomposed and amorphized in response to mechanical stimuli (Fig. 2a). ${ }^{13}$ The intensity of the diffraction pattern was recovered after heating the ground sample. The differential scanning calorimetry (DSC) thermogram of crystalline 1- $\alpha$ exhibited one endothermic peak that corresponds to the melting point $\left(T_{\mathrm{m}}=239{ }^{\circ} \mathrm{C}\right)$. Meanwhile, an exothermic cold-crystallization transition peak $\left(T_{\mathrm{c}}=108{ }^{\circ} \mathrm{C}\right)$ followed by an endothermic melting peak was observed in the DSC scan of the ground sample (Fig. $2 b$ and S6, ESI $\dagger$ ). Accordingly, the crystallization from the ground amorphous state should account for the recovery of the green emission after heating. 
(a)

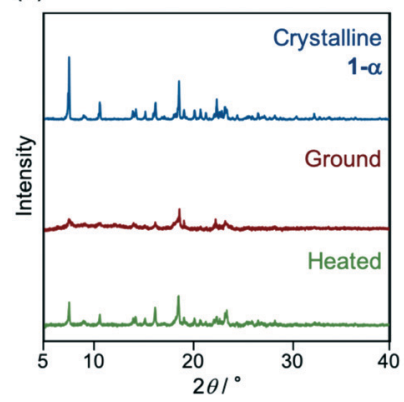

(b)

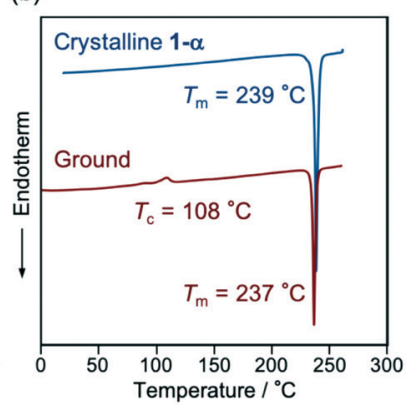

Fig. 2 (a) PXRD patterns and (b) DSC thermograms for the MCL of 1$\alpha$. The $T_{\mathrm{m}}$ and $T_{\mathrm{c}}$ values are noted near the corresponding peaks.

The lifetime decay curves of crystalline 1- $\alpha$ and the ground amorphous state fitted well to single- and double-exponential functions, respectively. The fluorescence lifetime $(\tau)$ of crystalline $1-\alpha$ is $7.0 \mathrm{~ns}$, whereas $\tau_{1}$ and $\tau_{2}$ of the ground sample are 4.6 and 8.6 ns, respectively (Fig. S7 and Table S1, ESI $\dagger)$. The minor component $\left(\tau_{2}=8.6 \mathrm{~ns}\right)$ would be attributed to the structural inhomogeneity of the amorphous sample. The radiative $\left(k_{\mathrm{r}}\right)$ and non-radiative rate constants $\left(k_{\mathrm{nr}}\right)$ of these states were calculated from $\Phi_{\mathrm{F}}$ and the intensityweighted mean fluorescence lifetime $\langle\tau\rangle\left[\Phi_{\mathrm{F}}=k_{\mathrm{r}} /\left(k_{\mathrm{r}}+k_{\mathrm{nr}}\right)=\right.$ $\langle\tau\rangle \times k_{\mathrm{r}}$; crystalline: $k_{\mathrm{r}}=8.5 \times 10^{7} \mathrm{~s}^{-1}, k_{\mathrm{nr}}=5.7 \times 10^{7} \mathrm{~s}^{-1}$; ground: $\left.k_{\mathrm{r}}=8.2 \times 10^{7} \mathrm{~s}^{-1}, k_{\mathrm{nr}}=8.6 \times 10^{7} \mathrm{~s}^{-1}\right]$. The larger $k_{\mathrm{nr}}$ value of the amorphous state accounts for its relatively smaller $\Phi_{\mathrm{F}}$ value compared with that of crystalline 1- $\alpha$, which would be attributed to the increased conformational flexibility and intermolecular interactions in the amorphous state.

\section{Crystal structure and emission properties of $1-\beta$}

Polymorphic crystals of $\mathbf{1}$ (abbreviated henceforth as 1- $\boldsymbol{\beta}$ ) that exhibit yellow emission were obtained by changing the crystallization solvent. The vapor diffusion of hexane into a chloroform solution of $\mathbf{1}$ afforded yellow-emissive crystals $\mathbf{1 - \beta}$ $\left(\lambda_{\mathrm{em}}=553 \mathrm{~nm}, \Phi_{\mathrm{F}}=0.33\right)$. The X-ray diffraction analysis of a single crystal revealed that the crystal system of $\mathbf{1 - \beta}$ is monoclinic ( $P 2_{1} / n$, Fig. S2, ESI $\dagger$ ). Although solvent molecules were included in the 1D channel structure of 1- $\boldsymbol{\beta}$ (Fig. 3a), the position of the solvent molecules could not be determined probably due to the dynamic nature of the solvent molecules in the channel structure. The SQUEEZE method ${ }^{14}$ was used to remove the disordered solvent molecules. The adjacent two molecules in 1- $\boldsymbol{\beta}$ formed antiparallel intermolecular stacks at the thienylbenzothiadiazole moieties (Fig. 3b). The thienylbenzothiadiazole moiety of $\mathbf{1 - \beta}$ is more planar than that of 1- $\alpha$. Namely, the dihedral angle between the planes of the benzothiadiazole and the thienyl rings is smaller for $\mathbf{1 - \beta}$ $\left(\phi_{2}=4.65^{\circ}\right)$ compared to that of $1-\alpha\left(\phi_{2}=35.18^{\circ}\right)$.

The planarization of the molecular structure in $\mathbf{1 - \beta}$ should explain the longer emission wavelength of $\mathbf{1 - \beta}$ compared to that of 1- $\alpha$. Time-dependent density functional theory (TDDFT) calculations at the CAM-B3LYP/6-31G(d) level of theory (a)

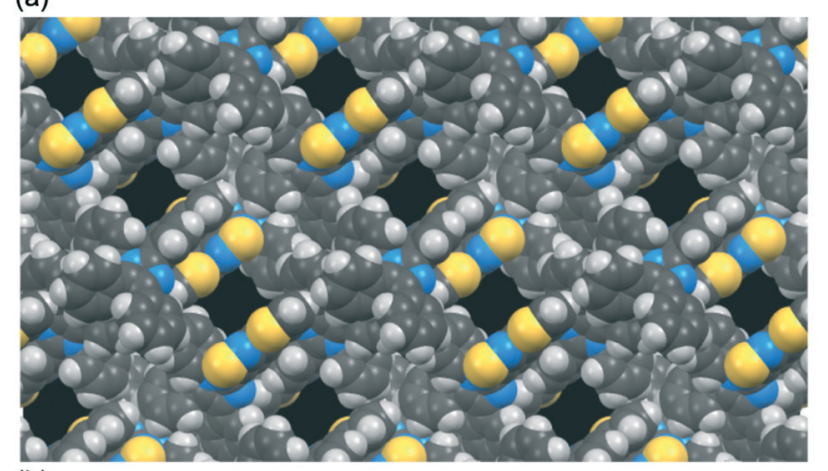

(b)

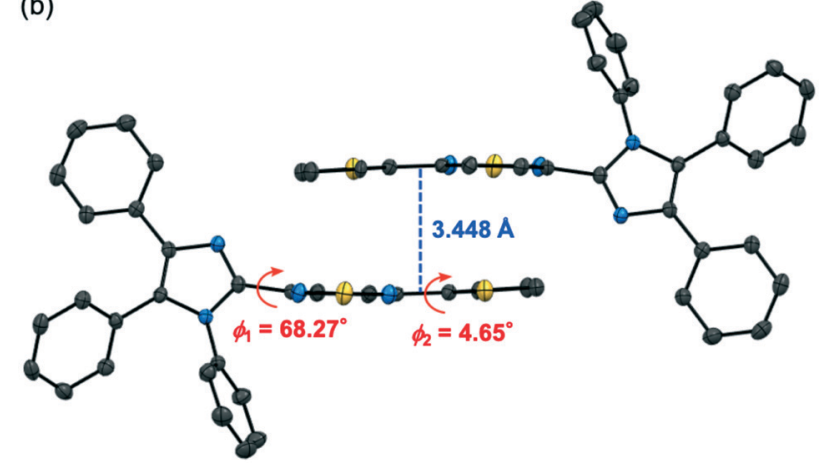

Fig. 3 (a) Space-filling representation of the packing structure of 1- $\beta$ viewed along the $b$-axis. (b) Front view of $1-\beta$ for the two molecules in spatial proximity with thermal ellipsoids at $50 \%$ probability. All hydrogen atoms are omitted for clarity. Color code: gray $=\mathrm{C}$; blue $=$ $\mathrm{N}$; yellow $=\mathrm{S}$.

were conducted using the molecular structures of 1 obtained by the X-ray diffraction analysis of $1-\alpha$ and $\mathbf{1 - \beta}$ (Fig. 4). The HOMOs of $\mathbf{1 - \alpha}$ and $\mathbf{1 - \boldsymbol { \beta }}$ are mainly located on the 4,5-diphenylimidazole moieties and partially distributed over the benzothiadiazole and thiophene rings. On the other hand, the LUMOs of $\mathbf{1 - \alpha}$ and $\mathbf{1 - \beta}$ are localized on the thienylbenzothiadiazole moieties. Notably, the calculated absorption wavelength of $\mathbf{1 - \beta}$ (calcd. $\lambda_{\mathrm{abs}}=387.07 \mathrm{~nm}$ ) is significantly shifted in the bathochromic direction relative to that of $1-\alpha$ (calcd. $\lambda_{\text {abs }}=375.63 \mathrm{~nm}$ ) (Table S2, ESI $\dagger$ ). The contribution of the charge-transfer HOMO to LUMO transition was larger for $1-\alpha(0.617)$ than that for $\mathbf{1 - \beta}(0.568)$ probably due to the smaller dihedral angle $\phi_{1}$ of $1-\alpha$ (1- $\alpha$ :

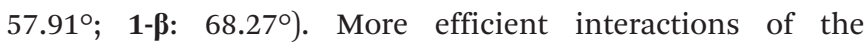
molecular orbitals would occur for 1- $\alpha$ between the electrondonating imidazole ring and the electron-accepting benzothiadiazole ring. Meanwhile, the planar structure of 1- $\beta$ at the thienylbenzothiadiazole moiety $\left(\phi_{2}=4.65^{\circ}\right)$ would account for the bathochromic shift of the calculated absorption wavelength of $\mathbf{1 - \beta}$.

The adjacent two molecules of $\mathbf{1}$ in $\mathbf{1 - \beta}$ exhibit more efficient overlaps between the molecular orbitals at the planar thienylbenzothiadiazole moieties, which would also contribute to the bathochromic shift of the emission wavelength compared to that of $1-\alpha$. The TD-DFT calculations for dimer $\mathbf{1}$ in $\mathbf{1}-\boldsymbol{\alpha}$ and $\mathbf{1 - \beta}$ were conducted at the same level 
(a) 1- $\alpha$ : calcd. $\lambda_{\text {abs }}=375.63 \mathrm{~nm}$

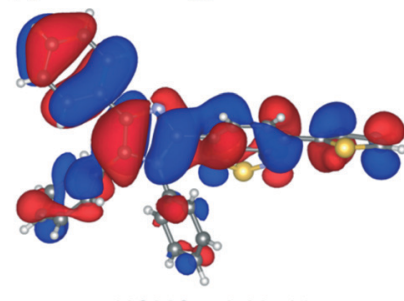

HOMO: $-6.60 \mathrm{eV}$

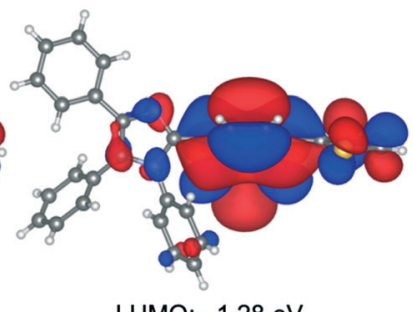

LUMO: $-1.28 \mathrm{eV}$

(b) 1- $\beta$ : calcd. $\lambda_{\text {abs }}=387.07 \mathrm{~nm}$
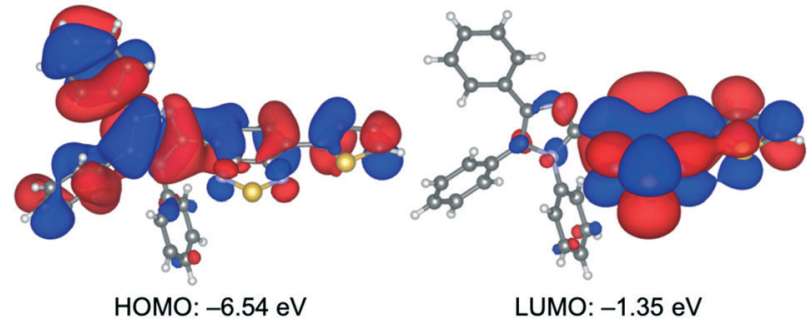

Fig. 4 The HOMOs and LUMOs of 1 in $1-\alpha$ (a) and $1-\beta$ (b) calculated at the CAM-B3LYP/6-31G(d) level. The structures are drawn using VESTA. $^{15}$

of theory by applying the basis set superposition error (BSSE) correction using the counterpoise method (Table S2, ESI $\dagger$ ). Although the calculated absorption wavelength of dimer 1- $\alpha$ (calcd. $\lambda_{\text {abs }}=379.96 \mathrm{~nm}$ ) was longer than that of monomer 1$\alpha$, this transition has zero oscillator strength. Meanwhile, the calculated absorption wavelength of dimer $\mathbf{1 - \beta}$ was $389.46 \mathrm{~nm}$ with an oscillator strength of 0.6463. Significant overlaps between the molecular orbitals were observed in the HOMO and LUMO of dimer $\mathbf{1 - \beta}$ (Fig. S8 $\dagger$ ).

\section{Stimuli-responsive emission-color switching of 1- $\beta$ and 1- $\gamma$}

Interestingly, the yellow-emissive crystals, $\mathbf{1 - \beta}$, can switch their emission properties in response to both mechanical and thermal stimuli (Fig. 5 and $\mathrm{S} 4 \mathrm{~b}, \mathrm{ESI} \dagger$ ). Upon grinding with a spatula, the emission color of 1- $\beta$ changed from yellow to orange $\left(\lambda_{\mathrm{em}}=585 \mathrm{~nm}, \Phi_{\mathrm{F}}=0.25\right)$. The PXRD analyses of the crystalline and ground samples indicated that the crystalline samples changed to an amorphous state after grinding (Fig. 6a; blue and red lines). When the ground samples were heated to $150{ }^{\circ} \mathrm{C}$ and then cooled to room

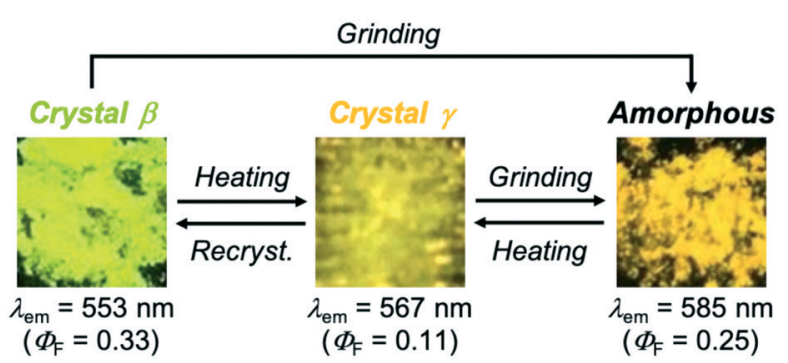

Fig. 5 Photographs of the mechanical and thermal stimuli-responsive emission color change of 1- $\beta$ and the MCL of $1-\gamma\left(\lambda_{\text {ex }}=365 \mathrm{~nm}\right)$. (a)

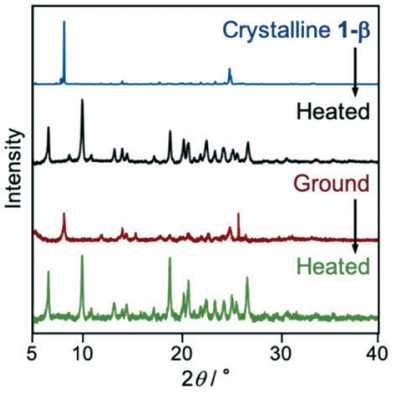

(b)

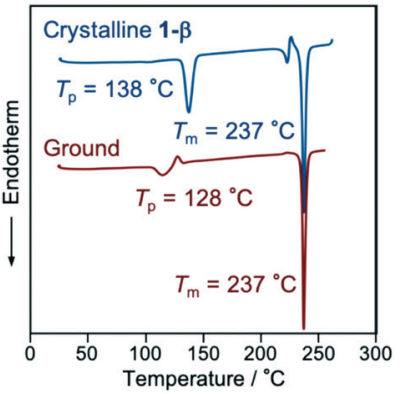

Fig. 6 (a) PXRD patterns and (b) DSC thermograms for the crystalline and ground samples of 1- $\beta$. The $T_{\mathrm{p}}$ and $T_{\mathrm{m}}$ values are noted near the corresponding peaks.

temperature, the emission color changed to yellow-orange emission $\left(\lambda_{\text {em }}=567 \mathrm{~nm}, \Phi_{\mathrm{F}}=0.11\right)$. Notably, the PXRD pattern of the heated sample was different from that of the initial crystalline 1- $\boldsymbol{\beta}$ (Fig. 6a; blue and green lines). This diffraction pattern is also different from that of $1-\alpha$, indicating that the ground state changed to another polymorphic form (abbreviated henceforth as $\mathbf{1}-\boldsymbol{\gamma}$ ). The DSC thermogram of ground 1- $\boldsymbol{\beta}$ showed a phase transition peak $\left(T_{\mathrm{p}}=128^{\circ} \mathrm{C}\right)$ from the amorphous state to $1-\gamma$ followed by the endothermic melting peak $\left(T_{\mathrm{m}}=23{ }^{\circ} \mathrm{C}\right.$; Fig. 6b). More interestingly, the diffraction pattern that indicates the formation of $1-\gamma$ was also observed after heating the initial crystalline $\mathbf{1 - \beta}$ to $150{ }^{\circ} \mathrm{C}$ (Fig. 6a; black line). The DSC thermogram of crystalline 1- $\boldsymbol{\beta}$ showed an endothermic peak at $138{ }^{\circ} \mathrm{C}$ prior to the endothermic melting peak of $\mathbf{1 - \beta}$ (Fig. 6b). The first endothermic peak $\left(T_{\mathrm{p}}\right)$ should correspond to the phase transition from $\mathbf{1 - \beta}$ to $\mathbf{1}-\boldsymbol{\gamma}$. The yellow-orangeemissive $1-\gamma$ changed to the orange-emissive amorphous state upon grinding, whereas recrystallization from solvents was required to restore 1- $\boldsymbol{\beta}$ from 1- $\boldsymbol{\gamma}$ (Fig. 5).

Although the recrystallization of $\mathbf{1}$ by vapor diffusion of hexane into a chloroform solution typically afforded $\mathbf{1 - \beta}$, a single crystal of $\mathbf{1}-\boldsymbol{\gamma}$ could also be obtained from the same solvent mixtures. The X-ray diffraction analysis showed that 1- $\gamma$ exhibits the monoclinic space group $P 2_{1} / c$, whereby the thienylbenzothiadiazole moiety of $\mathbf{1}$ exhibited a planar structure $\left(\phi_{2}=4.02^{\circ}\right)$ and the thienyl group was disordered over two positions (Fig. S3, ESI $\dagger$ ). The simulated PXRD patterns calculated from the single-crystal X-ray diffraction structures of $\mathbf{1}-\boldsymbol{\gamma}$ were in good agreement with the experimental PXRD patterns of $\mathbf{1} \boldsymbol{\gamma} \boldsymbol{\gamma}$ obtained by heating crystalline 1- $\boldsymbol{\beta}$ (Fig. S9 $\dagger$ ). The TD-DFT calculations indicated that the absorption wavelength of a molecule in $\mathbf{1 - \gamma}$ (Table $\mathrm{S} 2 ; \dagger$ calcd. $\lambda_{\mathrm{abs}}=397.77 \mathrm{~nm}$ ) should be longer than that in 1$\boldsymbol{\beta}$. The absorption and excitation spectra of $\mathbf{1}-\boldsymbol{\gamma}$ were shifted in the bathochromic direction compared to those of 1- $\boldsymbol{\beta}$ (Fig. S5 $\dagger$ ). These results would account for the bathochromically shifted emission of $\mathbf{1 - \gamma}$ relative to that of $\mathbf{1 - \beta}$. Although the dihedral angle $\phi_{2}$ of $1-\gamma\left(4.02^{\circ}\right)$ was similar to that of $\mathbf{1 - \beta}$ $\left(4.65^{\circ}\right)$, the smaller $\phi_{1}$ of $1-\gamma\left(58.83^{\circ}\right)$ than that of $1-\beta\left(68.27^{\circ}\right)$ would account for the longer absorption wavelength of $1-\gamma$ 
(a)
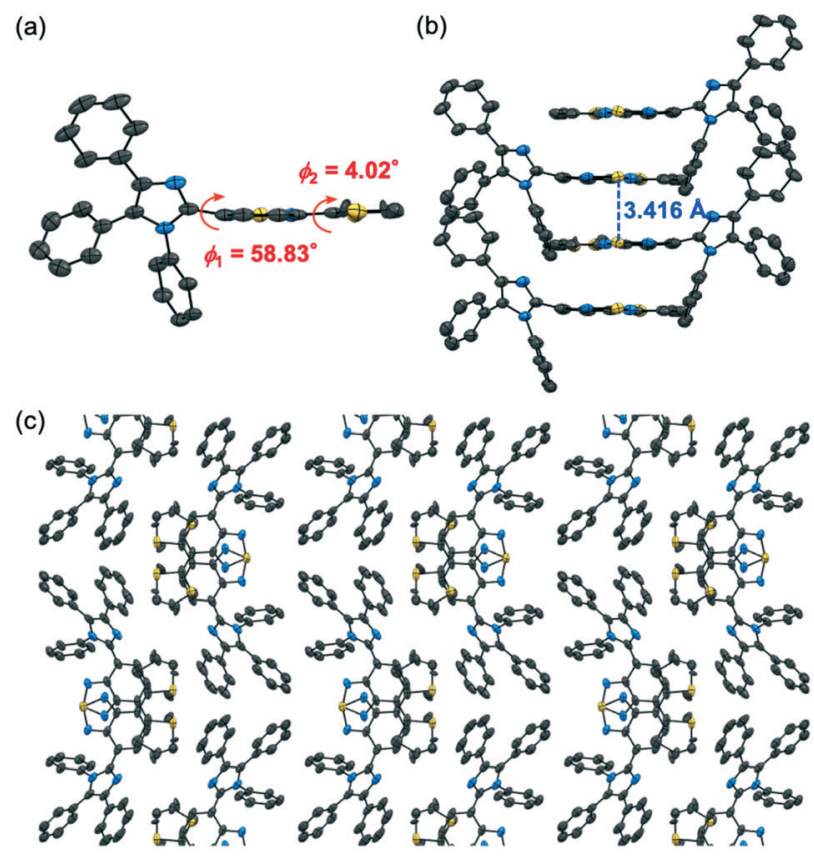

Fig. 7 (a) Molecular structure of 1- $\gamma$. (b) Intermolecular stacking structure of $1-\gamma$. (c) Packing structure of $1-\gamma$ viewed along the $c$-axis. Thermal ellipsoids at $50 \%$ probability. All hydrogen atoms are omitted for clarity. Color code: gray $=\mathrm{C}$; blue $=\mathrm{N}$; yellow $=\mathrm{S}$.

owing to the efficient charge-transfer transition from HOMO to LUMO (0.621). Meanwhile, the adjacent molecules in 1- $\boldsymbol{\gamma}$ formed extended intermolecular stacks at the thienylbenzothiadiazole moieties (Fig. $7 \mathrm{~b}$ and c). A dimer structure of $\mathbf{1}$ in 1- $\gamma$ showed a significant bathochromic shift in the calculated absorption wavelength $\left(\lambda_{\mathrm{abs}}=407.83 \mathrm{~nm}\right)$ compared with monomer $\mathbf{1}$ in $\mathbf{1}-\boldsymbol{\gamma}$ (Table $\mathrm{S} 2 \dagger$ ). The HOMO of dimer $\mathbf{1}-\boldsymbol{\gamma}$ was distributed on one molecule and the LUMO was mainly located on the benzothiadiazole ring of the other molecule and overlapped with the adjacent benzothiadiazole ring (Fig. S8c $\dagger$ ). Such intermolecular interactions should have a significant impact on the photophysical properties of 1- $\gamma$. The mean fluorescence lifetimes $\langle\tau\rangle$ of $\mathbf{1 - \beta}$ and $\mathbf{1 - \gamma}$ were 6.0 ns and 2.4 ns, respectively (Fig. S7 and Table S1, ESI $\dagger$ ). Although 1- $\boldsymbol{\beta}$ and 1- $\boldsymbol{\gamma}$ exhibited similar $k_{\mathrm{r}}$ values (1- $\boldsymbol{\beta}$ : $5.5 \times$ $\left.10^{7} \mathrm{~s}^{-1} ; 1-\gamma: 4.5 \times 10^{7} \mathrm{~s}^{-1}\right)$, the $k_{\mathrm{nr}}$ value of $1-\gamma\left(3.7 \times 10^{8} \mathrm{~s}^{-1}\right)$ was considerably larger than that of $1-\boldsymbol{\beta}\left(1.1 \times 10^{8} \mathrm{~s}^{-1}\right)$. Accordingly, the smaller $\Phi_{\mathrm{F}}$ value of $\mathbf{1 - \gamma}$ compared to that of 1- $\boldsymbol{\beta}$ would be attributed to the increased nonradiative decay processes of the excited molecules in $\mathbf{1}-\boldsymbol{\gamma}$ caused by the intermolecular interactions.

\section{Conclusions}

In summary, a thienyl-substituted donor-acceptor-type benzothiadiazole derivative $\mathbf{1}$ was synthesized as a new MCL dye that can form three types of crystals with different luminescence properties. Triclinic crystals 1- $\alpha(P \overline{1})$ were obtained by recrystallization from toluene/hexane, which exhibited typical MCL between green and yellow emission based on crystal-to-amorphous phase transitions. The formation of isolated intermolecular stacks between two adjacent molecules at the benzothiadiazole rings should account for the good fluorescence quantum yield of 1- $\alpha\left(\Phi_{\mathrm{F}}=0.60\right)$. Solventcontaining monoclinic crystals $\mathbf{1}-\boldsymbol{\beta}\left(P 2_{1} / n\right)$ were formed from chloroform/hexane. The yellow emission of $\mathbf{1 - \beta}$ switched to orange emission upon grinding, and the ground sample changed to yellow-orange-emissive crystals $1-\gamma\left(P 2_{1} / c\right)$ after heating. The transformation from $\mathbf{1 - \beta}$ to $1-\boldsymbol{\gamma}$ also occurred by heating $\mathbf{1}-\boldsymbol{\beta}$, and $\mathbf{1}-\boldsymbol{\gamma}$ changed to the amorphous state after grinding. The molecular conformation of 1 in the $\mathbf{1 - \alpha}$ and 1- $\boldsymbol{\beta}$ crystals is characterized by the different dihedral angles between the benzothiadiazole and thiophene planes (1- $\alpha$ : $35.18^{\circ} ; \mathbf{1 - \beta :} 4.65^{\circ}$ ). Based on the TD-DFT calculations, the planar molecular structure of $\mathbf{1 - \beta}$ should contribute to the bathochromically shifted emission compared to that of $1-\alpha$. Concerning the intermolecular interactions, $\mathbf{1 - \alpha}$ and 1- $\boldsymbol{\beta}$ formed isolated intermolecular stacks between two adjacent molecules at the benzothiadiazole and thienylbenzothiadiazole moieties, respectively. In contrast, extended intermolecular stacks were observed in the crystal structure of 1- $\gamma$. Moreover, the disorder of the thiophene ring was only observed in $1-\gamma$. Such structural differences should account for the difference in the emission properties of these polymorphic crystals. This study reiterates that the generation of polymorphic crystals is a facile method to obtain crystals with different MCL properties from a single compound. In addition to the triphenylimidazole structure that has been shown to generate polymorphic crystals, the introduction of the rotatable thienyl group should also contribute to the formation of polymorphs. This study provides useful insights into the design of single compounds that exhibit multi-color emission switching in response to different types of external stimuli. Such compounds are expected to be applied to advanced sensing technologies.

\section{Experimental}

\section{Instrumentation and materials}

All air-sensitive experiments were carried out under an argon atmosphere unless otherwise noted. IR spectra were recorded on a Nicolet iS10 FT-IR spectrometer. ${ }^{1} \mathrm{H}$ and ${ }^{13} \mathrm{C}$ NMR spectra were recorded on a Bruker DRX500 spectrometer using tetramethylsilane as an internal standard. A miniature fiber-optic spectrometer (FLAME-S-XR1-ES, Ocean Optics) and a handy UV lamp (365 nm, LUV-6, AS ONE) were used for the measurements of mechanochromic luminescence. Fluorescence and UV-vis absorption spectra were measured on a JASCO FP-8300 fluorescence spectrometer. For the measurement of UV-Vis absorption spectra in solution, an FUV-803 absorbance measurement cell block was used. The solid-state absorption spectra were obtained by measuring diffuse reflectance spectra using an FPA-810 powder sample cell block, in which a sample diluted in $\mathrm{BaSO}_{4}$ was loaded. The absolute fluorescence quantum yields were determined using a $100 \mathrm{~mm} \phi$ integrating sphere (JASCO ILF-835). Powder X-ray diffraction (PXRD) measurements were 
performed on a Rigaku SmartLab system using $\mathrm{CuK} \alpha$ radiation. Differential scanning calorimetry (DSC) data were recorded on a Seiko Instruments DSC-6100 equipped with a liquid nitrogen cooling unit (heating rate: $10{ }^{\circ} \mathrm{C} \mathrm{min}^{-1}$ ). Melting points were determined on a Stuart melting point apparatus SMP3 and are uncorrected. High-resolution electrospray ionization (HRMS-ESI) mass spectra were recorded on a Hitachi Nano Frontier LD spectrometer. Silica gel $60 \mathrm{~N}$ (spherical, neutral, 63-210 $\mu \mathrm{m}$ ) was used for column chromatography. 4-Bromo-7-(1,4,5-triphenyl-1 $H$-imidazol-2-yl) benzo $[c][1,2,5]$ thiadiazole was synthesized according to the literature procedure. ${ }^{12 e}$ Other reagents and solvents were commercially available and used as received.

\section{Synthesis of 4-(thiophen-2-yl)-7-(1,4,5-triphenyl-1H-imidazol- 2-yl)benzo[c] $[1,2,5]$ thiadiazole}

To a mixture of 4-bromo-7-(1,4,5-triphenyl- $1 H$-imidazol-2-yl) benzo[ $[c][1,2,5]$ thiadiazole $(100.8 \mathrm{mg}, \quad 0.20 \mathrm{mmol})$ and 2-thiopheneboronic acid (34.9 $\mathrm{mg}, 0.27 \mathrm{mmol}$ ) in DMF (2.0 $\mathrm{mL}$ ), an aqueous solution of $\mathrm{K}_{2} \mathrm{CO}_{3}(0.30 \mathrm{~mL}, 1.4 \mathrm{M})$ was added. The mixture was degassed under ultrasonication. $\mathrm{Pd}\left(\mathrm{PPh}_{3}\right)_{4}(27.4 \mathrm{mg}, 0.020 \mathrm{mmol})$ was added to the mixture, which was further degassed under ultrasonication. After the mixture was refluxed for $12 \mathrm{~h}$, water and dichloromethane were added to the mixture. The organic layer was separated, and the aqueous layer was extracted three times with dichloromethane. The combined organic layer was washed with water and brine, dried over anhydrous $\mathrm{Na}_{2} \mathrm{SO}_{4}$, and filtered. After removal of the solvent under reduced pressure, the crude product was purified by silica-gel column chromatography (dichloromethane/toluene $=9: 1$ ) to give 4-(thiophen-2-yl)-7-(1,4,5-triphenyl-1 $H$-imidazol-2-yl)benzo[c] $[1,2,5]$ thiadiazole $(\mathbf{1}: 84.4 \mathrm{mg}, 83 \%)$ as a yellow solid.

\section{4-(Thiophen-2-yl)-7-(1,4,5-triphenyl-1H-imidazol-2-yl)benzo[c] $[1,2,5]$ thiadiazole}

Yellow solid; m.p. 235.2-236.3 ${ }^{\circ} \mathrm{C}$; IR (KBr): $v_{\max } 3064,2946$, 2921, 1598, 1557, 1497, 1479, 1398, 1369, 1274, 1264, 1151, 1072, 1058, 1027, 882, 847, 836, $762 \mathrm{~cm}^{-1}$; ${ }^{1} \mathrm{H}$ NMR (500 $\left.\mathrm{MHz}, \mathrm{CDCl}_{3}\right): \delta(\mathrm{ppm}) 8.12-8.11(\mathrm{~m}, 1 H), 7.81(\mathrm{~d}, J=7.4 \mathrm{~Hz}$, $1 H), 7.72(\mathrm{~d}, J=7.4 \mathrm{~Hz}, 1 H), 7.63-7.61(\mathrm{~m}, 2 H), 7.46-7.45(\mathrm{~m}$, 1H), 7.28-7.23 (m, 5H), 7.21-7.18 (m, 4H), 7.09-7.05 (m, 3H), 7.02-7.00 (m, 2H); ${ }^{13} \mathrm{C}$ NMR (126 MHz, $\left.\mathrm{CDCl}_{3}\right): \delta(\mathrm{ppm})$ 153.8, $152.0,143.9,139.1,139.0,136.8,134.3,131.7,131.1$ (2C), 131.0, 130.5, 128.5 (2C), 128.4 (2C), 128.2, 128.10 (2C), 128.09, 128.03, 127.99 (2C), 127.9, 127.6 (2C), 127.4, 126.7, 124.9, 122.8 (one signal is hidden by incidental overlapping); HRMS-ESI $(\mathrm{m} / \mathrm{z})$ : $[\mathrm{M}+\mathrm{H}]^{+}$calcd for $\mathrm{C}_{31} \mathrm{H}_{21} \mathrm{~N}_{4} \mathrm{~S}_{2}, 513.1202$; found, 513.1229.

\section{X-ray crystallography}

A single crystal of 1- $\alpha$ was obtained by cooling a hot solution of 1 and was mounted on a glass fiber. All measurements were made on a Rigaku XtaLAB P200 diffractometer using multi-layer mirror monochromated $\mathrm{Cu}-\mathrm{K} \alpha$ radiation $(\lambda=$
$1.54184 \AA$ A). The data were collected at a temperature of $-50 \pm$ $1{ }^{\circ} \mathrm{C}$. The crystal-to-detector distance was $40.00 \mathrm{~mm}$. Readout was performed in the $0.172 \mathrm{~mm}$ pixel mode. Data were collected and processed using CrysAlisPro (Rigaku Oxford Diffraction). ${ }^{16}$ An empirical absorption correction was applied. The data were corrected for Lorentz and polarization effects. The structures of $\mathbf{1 - \alpha}$ and $\mathbf{1 - \beta}$ were solved by direct methods (SIR2011) ${ }^{17}$ and expanded using Fourier techniques. The non-hydrogen atoms were refined anisotropically. Hydrogen atoms were refined using the riding model. All calculations were performed using the CrystalStructure ${ }^{18}$ crystallographic software package except for refinement, which was performed using SHELXL Version 2014/7. ${ }^{19}$ Using Olex $2,{ }^{20}$ the structure of $1-\gamma$ was solved with the SHELXT ${ }^{21}$ structure solution program using Intrinsic Phasing and refined with the SHELXL ${ }^{22}$ refinement package using least squares minimisation.

Crystal data for 1- $\alpha$ (from toluene/hexane; CCDC 2073080): $\mathrm{C}_{31} \mathrm{H}_{20} \mathrm{~N}_{4} \mathrm{~S}_{2}, M=512.65$, triclinic, $a=10.49993(15) \AA, \quad b=$

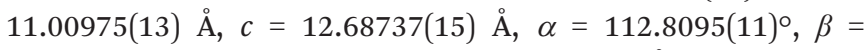
91.4574(11) ${ }^{\circ}, \gamma=109.9161(12)^{\circ}, V=1249.96(3) \AA^{3}$, space group $P \overline{1}$ (no. 2), $Z=2, D_{\mathrm{c}}=1.362 \mathrm{~g} \mathrm{~cm}^{-3}, F(000)=532.00, T=$ 223(1) K, $\mu(\mathrm{Cu}-\mathrm{K} \alpha)=21.483 \mathrm{~cm}^{-1}, 28281$ reflections measured, 4555 independent $\left(R_{\text {int }}=0.0425\right)$. The final refinement converged to $R_{1}=0.0357$ for $I>2.0 \sigma(I)$ and $\mathrm{w}_{2}=$ 0.1022 for all data.

Crystal data for 1- $\boldsymbol{\beta}$ (from $\mathrm{CHCl}_{3} /$ hexane; CCDC 2073081): $\mathrm{C}_{31} \mathrm{H}_{20} \mathrm{~N}_{4} \mathrm{~S}_{2}, M=512.65$, monoclinic, $a=18.6467(7) \AA, \quad b=$ 7.9281(2) A, $c=20.2852(8) \AA, \beta=114.132(5)^{\circ}, V=2736.7(2) \AA^{3}$, space group $P 2_{1} / n$ (no. 14 ), $Z=4, D_{\mathrm{c}}=1.244 \mathrm{~g} \mathrm{~cm}^{-3}, F(000)=$ 1064.00, $T=123(1) \mathrm{K}, \mu(\mathrm{Cu}-\mathrm{K} \alpha)=19.624 \mathrm{~cm}^{-1}, 30248$ reflections measured, 5026 independent $\left(R_{\text {int }}=0.0645\right)$. The final refinement converged to $R_{1}=0.0507$ for $I>2.0 \sigma(I)$ and $\mathrm{w} R_{2}=0.1474$ for all data.

Crystal data for $1-\gamma$ (from $\mathrm{CHCl}_{3} /$ hexane; CCDC 2073082): $\mathrm{C}_{31} \mathrm{H}_{20} \mathrm{~N}_{4} \mathrm{~S}_{2}, M=512.63$, monoclinic, $a=17.5816(6) \AA, \quad b=$ 20.1048(7) ̊, $c=6.9531(3) \AA, \beta=95.208(4)^{\circ}, V=2447.60(16)$ $\AA^{3}$, space group $P 2_{1} / c$ (no. 14 ), $Z=4, D_{\mathrm{c}}=1.391 \mathrm{~g} \mathrm{~cm}^{-3}, F(000)$ $=1064.0, T=223(1) \mathrm{K}, \mu(\mathrm{Cu}-\mathrm{K} \alpha)=21.95 \mathrm{~cm}^{-1}, 23370$ reflections measured, 5054 independent $\left(R_{\text {int }}=0.0576\right)$. The final refinement converged to $R_{1}=0.0538$ for $I>2.0 \sigma(I)$ and $\mathrm{w} R_{2}=0.1857$ for all data.

\section{Theoretical calculations}

The theoretical calculations were performed using the Gaussian 16 program. $^{23}$ The six lowest singlet-singlet transitions of $\mathbf{1}$ in the $\mathbf{1 - \alpha}, \mathbf{1 - \beta}$, and $\mathbf{1 - \gamma}$ crystals were calculated using time-dependent density functional theory (TD-DFT) calculations at the CAM-B3LYP/6-31G(d) level of theory (Table S1 $\uparrow$ ). The molecular structures, obtained from the single-crystal X-ray diffraction analysis, were used as a starting point. Here, the long-range-corrected hybrid functional CAM-B3LYP was used, as CAM-B3LYP often provides better results in TD-DFT calculations than B3LYP, which is conventionally used in DFT calculations. ${ }^{24}$ For the 
calculation of dimer structures, BSSE was taken into account using the counterpoise correction. ${ }^{25}$

\section{Author contributions}

Suguru Ito: conceptualization, funding acquisition, project administration, visualization, writing - original draft. Sayaka Nagai: conceptualization, investigation, visualization, writing - review \& editing. Takashi Ubukata: validation, writing review \& editing. Takashi Tachikawa: funding acquisition, investigation, validation, writing - review \& editing.

\section{Conflicts of interest}

There are no conflicts to declare.

\section{Acknowledgements}

This work was partly supported by JSPS KAKENHI Grant Numbers 20K05645 within the Grant-in-Aid for Scientific Research (C), JSPS KAKENHI Grant Numbers 18H04508, $20 \mathrm{H} 04665$, and $20 \mathrm{H} 04673$ within the Grant-in-Aid for Scientific Research on Innovative Areas "Soft Crystals: Area No. 2903". Part of this work was carried out by the joint research program No. R02019 of Molecular Photoscience Research Center, Kobe University.

\section{Notes and references}

1 For reviews, see: (a) S. Ito, Chem. Lett., 2021, 50, 649-660; (b) M. Annadhasan, S. Basak, N. Chandrasekhar and R. Chandrasekar, Adv. Opt. Mater., 2020, 8, 2000959; (c) L. Sun, F. Yang, X. Zhang and W. Hu, Mater. Chem. Front., 2020, 4, 715-728; (d) P. Naumov, D. P. Karothu, E. Ahmed, L. Catalano, P. Commins, J. Mahmoud Halabi, M. B. AlHandawi and L. Li, J. Am. Chem. Soc., 2020, 142, 13256-13272; (e) M. Kato, H. Ito, M. Hasegawa and K. Ishii, Chem. - Eur. J., 2019, 25, 5105-5112; $(f)$ C. Wang and Z. Li, Mater. Chem. Front., 2017, 1, 2174-2194; (g) Y. Sagara, S. Yamane, M. Mitani, C. Weder and T. Kato, Adv. Mater., 2016, 28, 1073-1095; (h) P. Naumov, S. Chizhik, M. K. Panda, N. K. Nath and E. Boldyreva, Chem. Rev., 2015, 115, 12440-12490.

2 For seminal examples of organic MCL crystals, see: (a) M. Tanioka, S. Kamino, A. Muranaka, Y. Ooyama, H. Ota, Y. Shirasaki, J. Horigome, M. Ueda, M. Uchiyama, D. Sawada and S. Enomoto, J. Am. Chem. Soc., 2015, 137, 6436-6439; (b) K. Nagura, S. Saito, H. Yusa, H. Yamawaki, H. Fujihisa, H. Sato, Y. Shimoikeda and S. Yamaguchi, J. Am. Chem. Soc., 2013, 135, 10322-10325; (c) Y. Dong, B. Xu, J. Zhang, X. Tan, L. Wang, J. Chen, H. Lv, S. Wen, B. Li, L. Ye, B. Zou and W. Tian, Angew. Chem., Int. Ed., 2012, 51, 10782-10785; (d) J. Wang, J. Mei, R. Hu, J. Z. Sun, A. Qin and B. Z. Tang, J. Am. Chem. Soc., 2012, 134, 9956-9966; (e) X. Luo, J. Li, C. Li, L. Heng, Y. Q. Dong, Z. Liu, Z. Bo and B. Z. Tang, Adv. Mater., 2011, 23, 3261-3265; $(f)$ G. Zhang, J. Lu, M. Sabat and C. L. Fraser, J. Am. Chem. Soc., 2010, 132, 2160-2162; $(g)$ S. J.
Yoon, J. W. Chung, J. Gierschner, K. S. Kim, M. G. Choi, D. Kim and S. Y. Park, J. Am. Chem. Soc., 2010, 132, 13675-13683; (h) Y. Ooyama, Y. Kagawa, H. Fukuoka, G. Ito and Y. Harima, Eur. J. Org. Chem., 2009, 5321-5326; (i) J. Kunzelman, M. Kinami, B. R. Crenshaw, J. D. Protasiewicz and C. Weder, Adv. Mater., 2008, 20, 119-122; $(j)$ Y. Sagara, T. Mutai, I. Yoshikawa and K. Araki, J. Am. Chem. Soc., 2007, 129, 1520-1521.

3 For seminal examples of organometallic MCL crystals, see: (a) T. Seki, Y. Takamatsu and H. Ito, J. Am. Chem. Soc., 2016, 138, 6252-6260; (b) T. Seki, T. Ozaki, T. Okura, K. Asakura, A. Sakon, H. Uekusa and H. Ito, Chem. Sci., 2015, 6, 2187-2195; (c) M. Krikorian, S. Liu and T. M. Swager, J. Am. Chem. Soc., 2014, 136, 2952-2955; (d) T. Seki, K. Sakurada and H. Ito, Angew. Chem., Int. Ed., 2013, 52, 12828-12832; (e) H. Ito, M. Muromoto, S. Kurenuma, S. Ishizaka, N. Kitamura, H. Sato and T. Seki, Nat. Commun., 2013, 4, 2009; $(f)$ B. Xu, Z. Chi, X. Zhang, H. Li, C. Chen, S. Liu, Y. Zhang and J. Xu, Chem. Commun., 2011, 47, 11080-11082; (g) S. Perruchas, X. F. L. Goff, S. Maron, I. Maurin, F. Guillen, A. Garcia, T. Gacoin and J. P. Boilot, J. Am. Chem. Soc., 2010, 132, 10967-10969; (h) H. Ito, T. Saito, N. Oshima, N. Kitamura, S. Ishizaka, Y. Hinatsu, M. Wakeshima, M. Kato, K. Tsuge and M. Sawamura, J. Am. Chem. Soc., 2008, 130, 10044-10045.

4 For recent examples of MCL crystals based on crystal-toamorphous phase transitions, see: (a) M. Yang, I. S. Park, Y. Miyashita, K. Tanaka and T. Yasuda, Angew. Chem., Int. Ed., 2020, 59, 13955-13961; (b) M. Ikeya, G. Katada and S. Ito, Chem. Commun., 2019, 55, 12296-12299; (c) B. Li and H. Ge, Sci. Adv., 2019, 5, eaaw2774.

5 M. R. Caira, in Design of Organic Solids, ed. E. Weber, Springer Verlag, Berlin, 1998, vol. 198, pp. 163-208, DOI: 10.1007/3-540-69178-2_5.

6 For reviews, see: (a) D. Yan and D. G. Evans, Mater. Horiz., 2014, 1, 46-57; (b) S. P. Anthony, ChemPlusChem, 2012, 77, 518-531.

7 For examples of (pseudo)polymorphic crystals that exhibit different emission properties, see: (a) X. He, A. C. Benniston, H. Saarenpää, H. Lemmetyinen, N. V. Tkachenko and U. Baisch, Chem. Sci., 2015, 6, 3525-3532; (b) T. Ono, M. Sugimoto and Y. Hisaeda, J. Am. Chem. Soc., 2015, 137, 9519-9522; (c) T. Mutai, H. Tomoda, T. Ohkawa, Y. Yabe and K. Araki, Angew. Chem., Int. Ed., 2008, 47, 9522-9524; (d) H. Zhang, Z. Zhang, K. Ye, J. Zhang and Y. Wang, Adv. Mater., 2006, 18, 2369-2372; (e) B. Lu, X. Fang and D. Yan, ACS Appl. Mater. Interfaces, 2020, 12, 31940-31951; $(f)$ S. Ma, Y. Liu, J. Zhang, B. Xu and W. Tian, J. Phys. Chem. Lett., 2020, 11, 10504-10510; ( $g$ ) S. Izumi, H. F. Higginbotham, A. Nyga, P. Stachelek, N. Tohnai, P. De Silva, P. Data, Y. Takeda and S. Minakata, J. Am. Chem. Soc., 2020, 142, 1482-1491; (h) S. K. B. Mane, Y. Mu, E. Ubba, Z. Yang, J. Zhao and Z. Chi, J. Mater. Chem. C, 2019, 7, 15219-15224; (i) Y. Dong, F. Zhu, Z. Chen, J. Yin and S. H. Liu, Mater. Chem. Front., 2019, 3, 1866-1871; (j) M. S. Kazantsev, A. A. Sonina, I. P. Koskin, P. S. Sherin, T. V. Rybalova, E. Benassi and E. A. Mostovich, 
Mater. Chem. Front., 2019, 3, 1545-1554; (k) R. R. Cui, Y. C. Lv, Y. S. Zhao, N. Zhao and N. Li, Mater. Chem. Front., 2018, 2, 910-916; (l) Z. Xu, Z. Zhang, X. Jin, Q. Liao and H. Fu, Chem. - Asian J., 2017, 12, 2985-2990.

8 For a review, see: R. Tan, S. Wang, H. Lan and S. Xiao, Curr. Org. Chem., 2016, 21, 236-248.

9 For examples of polymorphic crystals that exhibit different MCL properties, see: (a) H. Yu, X. Song, N. Xie, J. Wang, C. Li and Y. Wang, Adv. Funct. Mater., 2021, 31, 2007511; (b) R. Kobayashi, T. Fujii, H. Imoto and K. Naka, Eur. J. Inorg. Chem., 2021, 217-222; (c) J. Y. Zhu, C. X. Li, P. Z. Chen, Z. Ma, B. Zou, L. Y. Niu, G. Cui and Q. Z. Yang, Mater. Chem. Front., 2020, 4, 176-181; (d) M. Echeverri, C. Ruiz, S. GámezValenzuela, M. Alonso-Navarro, E. Gutierrez-Puebla, J. L. Serrano, M. C. Ruiz Delgado and B. Gómez-Lor, ACS Appl. Mater. Interfaces, 2020, 12, 10929-10937; (e) Y. Xiong, J. Huang, Y. Liu, B. Xiao, B. Xu, Z. Zhao and B. Z. Tang, J. Mater. Chem. C, 2020, 8, 2460-2466; $(f)$ X. Feng, Y. Chen, Y. Lei, Y. Zhou, W. Gao, M. Liu, X. Huang and H. Wu, Chem. Commun., 2020, 56, 13638-13641; $(g)$ K. Wang, Y. Xie, M. Liu, W. Tao, H. Zhang, M. Huang, J. You, Y. Liu, Y. Li, Z. Li and Y. Q. Dong, Adv. Opt. Mater., 2020, 8, 2000436; (h) Y. Chen, X. Zhang, M. Wang, J. Peng, Y. Zhou, X. Huang, W. Gao, M. Liu and H. Wu, J. Mater. Chem. C, 2019, 7, 12580-12587; (i) B. Shao, R. Jin, A. Li, Y. Liu, B. Li, S. Xu, W. $\mathrm{Xu}$, B. $\mathrm{Xu}$ and W. Tian, J. Mater. Chem. C, 2019, 7, 3263-3268; ( $j$ ) Y. Wang, W. Liu, L. Ren and G. Ge, Mater. Chem. Front., 2019, 3, 1661-1670; (k) L. Y. Hsu, S. Maity, Y. Matsunaga, Y. F. Hsu, Y. H. Liu, S. M. Peng, T. Shinmyozu and J. S. Yang, Chem. Sci., 2018, 9, 8990-9001; (l) W. Yang, C. Liu, S. Lu, J. Du, Q. Gao, R. Zhang, Y. Liu and C. Yang, J. Mater. Chem. C, 2018, 6, 290-298; (m) T. Seki, K. Kobayashi, T. Mashimo and H. Ito, Chem. Commun., 2018, 54, 11136-11139; (n) H. Tian, P. Wang, J. Liu, Y. Duan and Y. Q. Dong, J. Mater. Chem. C, 2017, 5, 12785-12791; (o) M. Louis, A. Brosseau, R. Guillot, F. Ito, C. Allain and R. Métivier, J. Phys. Chem. C, 2017, 121, 15897-15907; (p) O. Toma, N. Mercier and C. Botta, J. Mater. Chem. C, 2016, 4, 5940-5944; (q) K. Wang, H. Zhang, S. Chen, G. Yang, J. Zhang, W. Tian, Z. Su and Y. Wang, Adv. Mater., 2014, 26, 6168-6173; (r) X. Gu, J. Yao, G. Zhang, Y. Yan, C. Zhang, Q. Peng, Q. Liao, Y. Wu, Z. Xu, Y. Zhao, H. Fu and D. Zhang, Adv. Funct. Mater., 2012, 22, 4862-4872.

10 For examples of pseudopolymorphic crystals that exhibit different MCL properties, see: (a) X. Wang, C. Qi, Z. Fu, H. Zhang, J. Wang, H.-T. Feng, K. Wang, B. Zou, J. W. Y. Lam and B. Z. Tang, Mater. Horiz., 2021, 8, 630-638; (b) J. Wu, J. Yin, S. Chen, H. Xiao, B. Yan and Q. Yang, Dyes Pigm., 2021, 186, 108978; (c) G. Huang, Y. Jiang, S. Yang, B. S. Li and B. Z. Tang, Adv. Funct. Mater., 2019, 29, 1900516; (d) T. Seki, K. Ida and H. Ito, Mater. Chem. Front., 2018, 2, 1195-1200; (e) B. Huang, W. C. Chen, Z. Li, J. Zhang, W. Zhao, Y. Feng, B. Z. Tang and C. S. Lee, Angew. Chem., Int. Ed., 2018, 57, 12473-12477; $(f)$ R. Li, S. Xiao, Y. Li, Q. Lin, R. Zhang, J. Zhao, C. Yang, K. Zou, D. Li and T. Yi, Chem. Sci., 2014, 5, 3922-3928.
11 For examples of donor-acceptor-type organic MCL dyes, see: (a) J. Zhang, A. Li, H. Zou, J. Peng, J. Guo, W. Wu, H. Zhang, J. Zhang, X. Gu, W. Xu, S. Xu, S. H. Liu, A. Qin, J. W. Y. Lam and B. Z. Tang, Mater. Horiz., 2020, 7, 135-142; (b) T. Ishi-i, H. Tanaka, R. Youfu, N. Aizawa, T. Yasuda, S. Kato and T. Matsumoto, New J. Chem., 2019, 43, 4998-5010; (c) Z. H. Guo, Z. X. Jin, J. Y. Wang and J. Pei, Chem. Commun., 2014, 50, 6088-6090; (d) M. S. Kwon, J. Gierschner, J. Seo and S. Y. Park, J. Mater. Chem. C, 2014, 2, 2552-2557; (e) X. Zhang, Z. Ma, Y. Yang, X. Zhang, X. Jia and Y. Wei, J. Mater. Chem. C, 2014, 2, 8932-8938; $(f)$ Y. Ooyama and Y. Harima, J. Mater. Chem., 2011, 21, 8372-8380; (g) Y. Wang, D. Xu, H. Gao, Y. Wang, X. Liu, A. Han, C. Zhang and L. Zang, J. Phys. Chem. C, 2018, 122, 2297-2306; (h) Y. Takeda, T. Kaihara, M. Okazaki, H. Higginbotham, P. Data, N. Tohnai and S. Minakata, Chem. Commun., 2018, 54, 6847-6850; (i) M. Okazaki, Y. Takeda, P. Data, P. Pander, H. Higginbotham, A. P. Monkman and S. Minakata, Chem. Sci., 2017, 8, 2677-2686; (j) Z. Xie, C. Chen, S. Xu, J. Li, Y. Zhang, S. Liu, J. Xu and Z. Chi, Angew. Chem., Int. Ed., 2015, 54, 7181-7184; (k) Y. Lei, Y. Liu, Y. Guo, J. Chen, X. Huang, W. Gao, L. Qian, H. Wu, M. Liu and Y. Cheng, J. Phys. Chem. C, 2015, 119, 23138-23148; (l) Y. Jiang, D. Gindre, M. Allain, P. Liu, C. Cabanetos and J. Roncali, Adv. Mater., 2015, 27, 4285-4289; $(m)$ K. C. Naeem, A. Subhakumari, S. Varughese and V. C. Nair, J. Mater. Chem. C, 2015, 3, 10225-10231; (n) J. Sun, X. Lv, P. Wang, Y. Zhang, Y. Dai, Q. Wu, M. Ouyang and C. Zhang, J. Mater. Chem. C, 2014, 2, 5365-5371.

12 (a) S. Takahashi, S. Nagai, M. Asami and S. Ito, Mater. Adv., 2020, 1, 708-719; (b) S. Ito, S. Nagai, T. Ubukata, T. Ueno and H. Uekusa, Cryst. Growth Des., 2020, 20, 4443-4453; (c) S. Nagai, M. Yamashita, T. Tachikawa, T. Ubukata, M. Asami and S. Ito, J. Mater. Chem. C, 2019, 7, 4988-4998; (d) S. Ito, C. Nishimoto and S. Nagai, CrystEngComm, 2019, 21, 5699-5706; (e) S. Ito, S. Nagai, T. Ubukata and M. Asami, Chem. Lett., 2019, 48, 1492-1495; $(f)$ S. Ito, T. Taguchi, T. Yamada, T. Ubukata, Y. Yamaguchi and M. Asami, RSC Adv., 2017, 7, 16953-16962; $(g)$ S. Ito, T. Yamada, T. Taguchi, Y. Yamaguchi and M. Asami, Chem. - Asian J., 2016, 11, 1963-1970.

13 (a) Y. Wang, I. Zhang, B. Yu, X. Fang, X. Su, Y.-M. Zhang, T. Zhang, B. Yang, M. Li and S. X.-A. Zhang, J. Mater. Chem. C, 2015, 3, 12328-12334; (b) X.-P. Zhang, J.-F. Mei, J.-C. Lai, C.-H. Li and X.-Z. You, J. Mater. Chem. C, 2015, 3, 2350-2357; (c) Z. Chen, J. Zhang, M. Song, J. Yin, G.-A. Yu and S. H. Liu, Chem. Commun., 2015, 51, 326-329.

14 P. van der Sluis and A. L. Spek, Acta Crystallogr., Sect. A: Found. Crystallogr., 1990, 46, 194-201.

15 K. Momma and F. Izumi, J. Appl. Crystallogr., 2011, 44, 1272-1276.

16 CrysAlisPro: Data Collection and Processing Software, Rigaku Corporation, Tokyo 196-8666, Japan, 2015.

17 M. C. Burla, R. Caliandro, M. Camalli, B. Carrozzini, G. L. Cascarano, C. Giacovazzo, M. Mallamo, A. Mazzone, G. Polidori and R. Spagna, J. Appl. Crystallogr., 2012, 45, 357-361.

18 CrystalStructure 4.2.5: Crystal Structure Analysis Package, Rigaku Corporation, Tokyo 196-8666, Japan, 2000-2017. 
19 G. M. Sheldrick, Acta Crystallogr., Sect. A: Found. Crystallogr., 2008, 64, 112-122.

20 O. V. Dolomanov, L. J. Bourhis, R. J. Gildea, J. A. K. Howard and H. Puschmann, J. Appl. Crystallogr., 2009, 42, 339-341.

21 G. M. Sheldrick, Acta Crystallogr., Sect. A: Found. Crystallogr., 2015, 71, 3-8.

22 G. M. Sheldrick, Acta Crystallogr., Sect. C: Struct. Chem., 2015, 71, 3-8.

23 M. J. Frisch, G. W. Trucks, H. B. Schlegel, G. E. Scuseria, M. A. Robb, J. R. Cheeseman, G. Scalmani, V. Barone, G. A. Petersson, H. Nakatsuji, X. Li, M. Caricato, A. V. Marenich, J. Bloino, B. G. Janesko, R. Gomperts, B. Mennucci, H. P. Hratchian, J. V. Ortiz, A. F. Izmaylov, J. L. Sonnenberg, D. Williams-Young, F. Ding, F. Lipparini, F. Egidi, J. Goings, B.
Peng, A. Petrone, T. Henderson, D. Ranasinghe, V. G. Zakrzewski, J. Gao, N. Rega, G. Zheng, W. Liang, M. Hada, M. Ehara, K. Toyota, R. Fukuda, J. Hasegawa, M. Ishida, T. Nakajima, Y. Honda, O. Kitao, H. Nakai, T. Vreven, K. Throssell, J. A. Montgomery, Jr., J. E. Peralta, F. Ogliaro, M. J. Bearpark, J. J. Heyd, E. N. Brothers, K. N. Kudin, V. N. Staroverov, T. A. Keith, R. Kobayashi, J. Normand, K. Raghavachari, A. P. Rendell, J. C. Burant, S. S. Iyengar, J. Tomasi, M. Cossi, J. M. Millam, M. Klene, C. Adamo, R. Cammi, J. W. Ochterski, R. L. Martin, K. Morokuma, O. Farkas, J. B. Foresman and D. J. Fox, Gaussian 16, Revision A.03, Gaussian, Inc., Wallingford CT, 2016.

24 D. Jacquemin, E. A. Perpète, G. E. Scuseria, I. Ciofini and C. Adamo, J. Chem. Theory Comput., 2008, 4, 123-135.

25 S. F. Boys and F. Bernardi, Mol. Phys., 1970, 19, 553-566. 